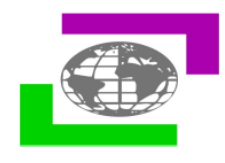

\title{
Management of Peripheral Neuropathy and Cardiovascular Effects in Vitamin B12 Deficiency
}

\section{${ }^{*}$ Nishant Kumar Singh, ${ }^{* 2}$ Hirni J. Patel, ${ }^{3}$ Mohit Buddhadev, ${ }^{3}$ S P Srinivas Nayak, ${ }^{4}$ Gunosindhu Chakraborthy}

${ }^{1}$ PharmD Student, Parul Institute of Pharmacy and Research, Parul University, Vadodara, Gujarat.

${ }^{2}$ PharmD Intern, Parul Institute of Pharmacy and Research, Parul University, Vadodara, Gujarat.

${ }^{3}$ Assistant Professor, Dept. of Pharmacy Practice, Parul Institute of Pharmacy and Research, Parul University, Vadodara, Gujarat.

${ }^{4}$ Professor \& Pincipal, Parul Institute of Pharmacy and Research, Parul University, Vadodara, Gujarat.

Article Info: Received 04 September 2021; Accepted 11 October 2021

DOI: https://doi.org/10.32553/jbpr.v10i5.884

Corresponding author: S P Srinivas Nayak

Conflict of interest statement: No conflict of interest

\begin{abstract}
Peripheral nerves are susceptible to damage by a wide array of toxins, medications, and vitamin deficiencies. Vitamin B12 (VB12) deficiency neuropathy is a rare debilitating disease that affects mostly the elderly. It is important to consider these etiologies when approaching patients with a variety of neuropathic presentations in this review were have included most relevant and latest information on mechanisms causing Peripheral neuropathy in VB12 deficiency. We also have included cardiovascular disorders and their management. Hyperhomocysteinemia has been implicated in endothelial dysfunction and cardiovascular disease. The association of homocysteine (Hcy) and VB12 with cardiovascular risk factors in patients with coronary artery disease (CAD) has also been studied
\end{abstract}

Keywords: Peripheral Neuropathy, Vitamin B12 Deficiency, Cardiovascular Disease and Homocysteine.

\section{Introduction}

Vitamin B12 (VB12) is an essential watersoluble vitamin important in cellular metabolism and maintenance of the integrity of the nervous system [1]. It is important in the synthesis of DNA and thus cell division [2]. Deficiency in vitamin $\mathrm{B} 12$ is associated with impaired erythropoiesis and nervous system demyelination, which account for most of its clinical manifestations [3, 4]. Globally, the most common aetiology of VB12 deficiency is lack of intrinsic factor in patients with pernicious anaemia; a common finding in the elderly [4]. Other aetiologies include dietary deficiency and mal-absorption [5].

Depletion of body B12 stores resulting from insufficient capture of the vitamin from dietary sources because of either inadequate intake or malabsorption eventually leads to a state of deficiency. When a certain threshold of 
deficiency is reached, the supply of B12 becomes inadequate to support biochemical pathways requiring the vitamin, leading to disruption of the functional and ultimately the structural integrity of cells. Absent of any underlying perturbation of B12-dependent pathways that occur in individuals who harbor inborn errors involving intracellular B12 assimilation and processing [6][7], the major determinant of the severity of B12 deficiency and whether it leads to either megaloblastic anemia, demyelinating neurological disease, or both appears to be whether there is abrogation of the normal physiological axis of B12 absorption. Normal B12 absorption requires intact gastric production of intrinsic factor as well as a functioning cubam receptor for the B12-intrinsic factor complex in the terminal ileum.[8],[9],[10] Clinically, VB12 deficiency presents mainly with neurological and psychiatric manifestations [5]. Neurological impairment usually presents as paraesthesia, numbness and ataxia $[5,11]$. Laboratory investigations play an important role in the diagnosis and determination of the aetiologies of this deficiency. Laboratory investigations vital in diagnosing VB12 deficiency include mean corpuscular volume (MCV), peripheral blood smear (ovalomacrocytosis and hypersegmented neutrophils), cyanocobalamin levels, serum methylmalonic acid and homocysteine [12]. Therapeutic trials have also been used for the diagnosis of VB12 deficiency [12]. Early diagnosis of VB12 deficiency is pivotal for timely management and in preventing long term complications which could account for significant morbidity.

\section{MECHANISM OF VITAMIN B12 DEFICIENCY}

Causes of vitamin B12 deficiency can be organized by where the absorption defect occurs. A diet containing minimal animal products provides sufficient VB12, so severe deficiency due to poor intake occurs only in the case of strict veganism. Within the stomach there are several etiologies that degrade the ability of VB12 to bind with intrinsic factor, including pernicious anemia, atrophic gastritis, prolonged antacid use (proton-pump inhibitor or $\mathrm{H} 2$-antagonists),[13] and gastric bypass. The final absorption of VB12 in the terminal ileum may be interrupted by Crohn disease or surgical resection.[14] The main pathology of vitamin B12 deficiency is subacute combined degeneration within the spinal cord with loss of both corticospinal tracts and posterior columns with a concomitant axonal sensorimotor peripheral neuropathy. It is important to note that because of the involvement of the cervical spinal cord early in disease, sensory symptoms in both hands and feet may present simultaneously and provide a clue to etiology.[15]

\section{SIGNS AND SYMPTOMS WITH VITAMIN B12 DEFICIENCY}

The main neurological symptoms include: paraesthesia [16-19], ataxia [17-19], and limb weakness [17, 18]. The most prevalent psychiatric symptoms associated with B12 deficiency include, delusions $[19,20]$, irritability [20, 21], and decreased interest [22, 23]. Other manifestations included depression $[19,23]$ and sleep disturbances [19, 23]. (Table.1) These neurological symptoms are associated with other common illnesses like HIV infection, diabetes, syphilis, alcoholism, and some medications, thus posing a diagnostic challenge [24].

Table 1: Signs and Symptoms with VB12 Deficiency

\begin{tabular}{|l|l|l|l|}
\hline Sl.No. & Neurological Symotoms & Psychiatric Symptoms & Other Manifestations \\
\hline 1 & paraesthesia & delusions & depression \\
\hline 2 & ataxia & irritability & sleep disturbances \\
\hline 2 & limb weakness & decreased interest & - \\
\hline
\end{tabular}




\section{DIAGNOSTIC CRITERIA}

Ovalo-macrocytosis and hyper-segmented neutrophils are important findings in VB12 deficiency [5] Splenomegaly and/or hepatomegaly have also been reported in cases with severe cobalamin deficiency [25], especially in settings were serum cyanocobalamin, methylmalonic and homocystein levels cannot be assessed. However, studies have designated that serum levels of VB12 can be unreliable for the assessment of VB12 deficiency [26]. Serum Transcobalamin II and methylmalonic acid levels are at present considered the most specific laboratory indices [26]. Nonetheless, Hypersegmented neutrophils is reported to have a sensitivity of $98 \%$ [27], compared to serum cyanocobalamin with a sensitivity of $90-95 \%$ [5]. Thus, making peripheral blood smear analysis a cost effective tool in the diagnosis of VB12 deficiency, In addition to intramedullary haemolysis due to ineffective erythropoiesis, homocysteine accumulation due to vitamin B12 or folate deficiency is found in VB12 Deficiency [28].

\section{CARDIOVASCULAR RISK IN VITAMIN B12 DEFICIENCY}

Homocysteine (Hcy) is a sulfhydryl containing amino acid produced by demethylation of an essential amino acid (methionine). Methylation of Hcy, catalyzed by methionine synthetase produces methionine [29]. Folate and vitamin B12 are essential components in the metabolism of Hcy, which occurs through remethylation to methionine or trans-sulfuration to cysteine. The enzyme methylene-tetrahydro-folate-reductase (MTHFR) is responsible for the reduction of 5,10-methylene-THF to 5-methyl-THF, where vitamin B12 acts as a cofactor [30]. Hcymediated enhanced lipid peroxidation and generation of free radicals results in inflammation and acute endothelial dysfunction, which accelerates atherosclerotic process predisposing to cardiovascular disease. The first clinical study by Wilcken and Wilcken in 1976, supported the theory that coronary artery disease (CAD) is associated with higher levels of Hcy
[31]. It has also been demonstrated that in the presence of traditional risk factors, Hcy plays a permissive role in endothelial damage. Low vitamin B12 concentration and hyperhomocysteinemia are common in Indian men, particularly in vegetarians and urban residents [32]. Many studies have been undertaken to examine the relation between plasma Hcy and coronary heart disease [33,34]. The general outcome supports the hypothesis that an elevated plasma Hcy concentration leads to an increased risk of cardiovascular disease. However, there are few studies that showed the association of Hcy, vitamin B12, and folic acid with cardiovascular risk factors in patients with known CAD. [34]

\section{ROLE OF HYPERHOMOCYSTENEMIA IN CARDIOVASCULAR DISORDER}

Increased plasma Hcy levels are positively associated with new onset CAD, recurrent cardiovascular events, extent of myocardial damage, and mortality in patients with ischemic heart disease [35,36]. Elevated Hcy levels are also related to intima media thickness [37] and to severity of CAD in Japanese patients [38], but were unrelated to major cardiovascular adverse events in patients with $\mathrm{CAD}$ who had undergone percutaneous coronary intervention [39]. However, few studies with small numbers of subjects were able to demonstrate this relation $[29,40]$. It has been postulated that higher Hcy levels lead to epigenetic modification by macromolecular global DNA methylation, which is associated with CAD in Indian patients [41]. It has been suggested that inadequate plasma concentration of VB12 is a contributing factor in approximately $2 / 3$ of all cases of hyperhomocysteinemia [42] and low vitamin B12 concentration contributed $28 \%$ to the risk of hyperhomocysteinemia [32].

\section{MANAGEMENT OF VB12 DEFICIENCY AND SOURCES}

In humans, VB12 is needed as a cofactor for two reactions: methylcobalamin is the cofactor for the cytoplasmic enzyme, methionine synthase, while adenosylcobalamin is the cofactor for the 
mitochondrial enzyme, methylmalonyl coenzyme A mutase $[43,44]$

A Severe VB12 deficiency in a 15-year-old boy case report [45]. Intramuscular cyanocobalamin was started $(0.5 \mu \mathrm{g} / \mathrm{kg} /$ day for 2 days followed by $100 \mu \mathrm{g} /$ day for 2 days and $1000 \mu \mathrm{g} /$ day for 1 week; thereafter, he received $1000 \mu \mathrm{g}$ cyanocobalamin weekly for 1 month, and received once every month for 6 months). In the second week of therapy, oral iron (ferrous glycine sulfate; $4 \mathrm{mg} / \mathrm{kg}$ /day of elemental iron) and folic acid ( $5 \mathrm{mg} /$ day) were initiated due to the expected increase in iron utilisation and borderline serum folic acid level (tested as 2.8 $\mathrm{ng} / \mathrm{mL} 5$ days after treatment initiation), respectively.[45] VB12is synthesised by certain bacteria in the gastrointestinal tract of animals and is then absorbed by the host animal. Vitamin B12 is concentrated in animal tissues, hence VB12 is found only in foods of animal origin [11]. Foods that are high in VB12 $(\mu \mathrm{g} / 100 \mathrm{~g})$ include: liver (26-58), beef and lamb (1-3), chicken (trace-1), eggs (1-2.5) and dairy foods (0.3-2.4).

There are no naturally occurring bioactive forms of VB12 from plant sources. Some plant foods contain added VB12 and others e.g., seaweed and mushrooms contain vitamin B12 analogues that are inactive in humans, although 2 studies suggest certain types of Japanese seaweed (nori) have prevented vitamin B12 deficiency in vegans [18]. Some foods that are contaminated or fermented by bacteria e.g., tempeh and Thai fish sauce, have been reported to contain vitamin B12[18], although these may have low affinity with IF and may be poorly absorbed [19].

A number of methods have been used to determine the vitamin B12 content of foods. Microbiological assays using vitamin B12 requiring bacteria were used, however, they are no longer the reference method as measurement uncertainty is high. Radio isotope dilution assays with labeled VB12 and hog IF are used [20]. Further advances are expected with the development of more specific monoclonal antibodies tests using specific binding proteins [21].

\section{VB12 REQUIREMENT}

The Recommended Dietary Intake (RDI) is set to prevent megaloblastic anaemia and maintain adequate serum VB12 concentrations. It is assumed that $50 \%$ of dietary VB12 is absorbed. The RDI and estimated average requirement (EAR) do not vary once adulthood is reached. However, the US and Australian Nutrient Reference Values suggest that older adults with atrophic gastritis may require higher intakes of VB12-rich foods, vitamin B12 fortified foods or supplements [3,22]. The US Institute of Medicine has recommended that adults over 51 years consume most of their VB12 from fortified foods or from supplements, again recognising the high rates of malabsorption due to gastritis that occurs with age. VB12 stores last several years and the development of deficiency is slow, however the combination of malabsorption and inadequate dietary intake will hasten deficiency [3].

\section{INTERACTIONS WITH VB12}

PPI medications are commonly used in the elderly for the treatment of gastro-oesophageal reflux disease. PPI medications act by reducing the secretion of gastric acid and pepsin, theoretically leading to a decrease in the absorption of protein-bound VB12. [30-33]. Metformin is a biguanide used for the treatment of non-insulin dependent diabetes and some patients taking this medication develop megaloblastic anaemia [34,35]. This may relate to intestinal mobility changes or bacterial overgrowth competing for vitamin B12 in the gastrointestinal tract. It has also been shown that calcium improves the uptake of VB12 in metformin users [35]. Nitrous oxide anesthesia inhibits methionine synthase and Lmethylmalonyl-CoA mutase and produces deficiency symptoms despite concentrations of serum vitamin B12 in the normal range [36]. Antiepileptic drugs have been associated with low concentrations of VB12, but this is controversial with some studies showing no change and others increased levels of VB12 [37]. 


\section{DISCUSSION AND CONCLUSION}

VB12 is an very essential water soluble vitamin important in cellular metabolism and maintenance of the integrity of the nervous system. It is important in the synthesis of DNA and thus cell division. Deficiency of VB12 causes impaired erythropoiesis and nervous system demyelination, PPIS, Metformin and Nitrous oxide decrease in the absorption of protein-bound VB12 and deficiency. Vitamin B12 is concentrated in animal tissues, hence, VB12 is found only in foods of animal origin. VB12 is essential components in the metabolism of homocysteine (Hcy). Hyperhomocysteinemia has been implicated in endothelial dysfunction and cardiovascular disease VB12 deficiency and hyperhomocysteinemia were associated with traditional and non-traditional cardiovascular risk factors and were independently associated with dyslipidemia even after adjustment for all other risk factors in Indian patients with CAD. There has been renewed interest in vitamin B12 since the reporting of associations between homocysteine and chronic disease, particularly vascular disease. Vegetarians are at risk of VB12 deficiency as are other groups with low intakes of animal foods or those with restrictive dietary patterns. Malabsorption of VB12 is most commonly seen in the elderly, secondary to gastric achlorhydria, proper diagnosis and Management can help patients from peripheral neuropathy and cardiovascular disorders.

\section{REFERENCES:}

1. Rusher DR, Pawlak R. A review of 89 published case studies of vitamin B12 deficiency. J Hum Nutr Food Sci. 2013;1(2):1008.

2. Hvas AM, Nexo E. Diagnosis and treatment of vitamin B12 deficiency: an update. Haematologica. 2006;91(11):1506-1512.

3. Headstrom PD, Rulyak SJ, Lee SD. Prevalence of and risk factors for vitamin $\mathrm{B}(12)$ deficiency in patients with Crohn's disease. Inflamm Bowel Dis. 2008;14:217223. doi: 10.1002/ibd.20282.
4. Stabler Sally P. Vitamin B12 deficiency. N Engl J Med. 2013;368:149-160. doi: 10.1056/NEJMcp1113996.

5. Lindenbaum J, Healton EB, Savage DG, et al. Neuropsychiatric disorders caused by cobalamin deficiency in the absence of anemia or macrocytosis. N Engl J Med. 1988;318:1720-1728. doi: 10.1056/NEJM198806303182604

6. Watkins D, Rosenblatt DS. Inborn errors of cobalamin absorption and metabolism. Am J Med Genet C Semin Med Genet. 2011;157C(1):33-44.

7. Froese DS, Gravel RA. Genetic disorders of vitamin B12 metabolism: eight complementation groups--eight genes. Expert Rev Mol Med. 2010;12:e37.

8. Green R, Miller JW. Vitamin B12. In: Zempleni J, Suttie JW, Gregory JF, Stover PJ, eds. Handbook of Vitamins. 5th ed. ed. Boca Raton, FL: Taylor \& Francis; 2014:447-490.

9. Nielsen MJ, Rasmussen MR, Andersen CB, Nexø E, Moestrup SK. Vitamin B12 transport from food to the body's cells--a sophisticated, multistep pathway. Nat Rev Gastroenterol Hepatol. 2012;9(6):345-354

10. Fyfe JC, Madsen M, Højrup P, et al. The functional cobalamin (vitamin B12)intrinsic factor receptor is a novel complex of cubilin and amnionless. Blood. 2004;103(5):1573-1579.

11. Healton EB, Savage DG, Brust JC, Garrett TJ, Lindenbaum J. Neurologic aspects of cobalamin deficiency. Medicine. 1991;70:229-245. doi: 10.1097/00005792-199107000-00001.

12. Snow FC. Laboratory diagnosis of vitamin B12 and folate deficiency. Arch Intern Med. 1999;159:1289-1298. doi: 10.1001/archinte.159.12.1289.

13. Lam JR, Schneider JL, Zhao W, Corley DA. Proton pump inhibitor and histamine 2 receptor antagonist use and vitamin B12 deficiency. JAMA 2013; 310 (22): 24352442

14. Nielsen MJ, Rasmussen MR, Andersen CB, et al. Vitamin B12 transport from food to the 
body's cells - a sophisticated, multistep pathway. Nat Rev Gastroenterol Hepatol 2012; 9 (6): 345-354

15. Saperstein DS, Wolfe GI, Gronseth GS, et al. Challenges in the identification of cobalamin-deficiency polyneuropathy. Arch Neurol 2003; 60 (9): 1296- 1301

16. Green R, Kara N, Cocks H. Vitamin B, deficiency: an unusual cause of vocal fold palsy. J Laryngol Otol. 2011;125:13091311. doi: 10.1017/S0022215111001824.

17. Wong CL, Van Spall HG, Hassan KA, Coret-Simon J, Sahlas DJ, Shumak SL. A young man with deep vein thrombosis, hyperhomocysteinemia and cobalamin deficiency. Can Med Assoc J. 2008;178:279-281. doi: 10.1503/cmaj.071415.

18. Celik M, Barkut IK, Oncel C, Forta H. Involuntary movements associated with vitamin B12 deficiency. Parkinsonism Relat Disord. 2003;10:55-57.

19. Srikanth SG, Jayakumar PN, Vasudev MK, Taly AB, Chandrashekar HS. MRI in subacute combined degeneration of spinal cord: a case report and review of literature. Neurol India. 2002;50:310-312.

20. Goebels N, Soyka M. Dementia associated with vitamin B12 deficiency: presentation of two cases and review of the literature. $\mathrm{J}$ Neuropsychiatry Clin Neurosci. 2000;12 :389-394. doi: 10.1176/jnp.12.3.389.

21. Berry N, Sagar R, Tripathi BM. Catatonia and other psychiatric symptoms with vitamin B12 deficiency. Acta Psychiatr Scand. 2003;108:156-159. doi: 10.1034/ j.1600-0447.2003.00089.x.

22. Sahoo MK, Avasthi A, Singh P. Negative symptoms presenting as neuropsychiatric manifestation of vitamin B12 deficiency. Indian J Psychiatry. 2011;53:370-371. doi: 10.4103/0019-5545.91914.

23. Milanlioglu A. Vitamin B12 deficiency and depression. J Clin Exp Investig. 2011;2:455456. doi: 10.5799/ahinjs.01.2011.04.0095.

24. Wilkinson Iain, Lennox Graham. Essential Neurology. 4. Oxford: Blackwell; 2005. p. p161.
25. Belen B, Hismi BO, Kocak U. Severe vitamin B12 deficiency with pancytopenia, hepatosplenomegaly and leukoerythroblastosis in two Syrian refugee infants: a challenge to differentiate from acute leukaemia. BMJ Case Rep 2014;2014 pii: bcr2014203742 10.1136/bcr-2014203742

26. Pawlak R, James PS, Raj S, Cullum-Dugan D, Lucas D. Understanding vitamin B12. Am J Lifestyle Med. 2013;7:60-65. doi: 10.1177/1559827612450688.

27. Thompson WG, Cassino C, Babitz L, et al. Hypersegmented neutrophils and vitamin B12 deficiency. Acta Haematol. 1989;81: 186-191. doi: 10.1159/000205559.

28. Olinescu R, Kummerow FA, Handler B et al. . The hemolytic activity of homocysteine is increased by the activated polymorphonuclear leukocytes. Biochem Biophys Res Commun 1996;226:912-16. 10.1006/bbrc.1996.1449.

29. Ng K.C. Yong Q.W. Chan S.P. Cheng A. Homocysteine, folate and vitamin B12 as risk factors for acute myocardial infarction in a southeast Asian population. Ann Acad Med Singapore. 2002; 31: 636-640

30. Sadeghian S. Fallahi F. Salarifar M. Davoodi G. MahmoodiaM Fallah N. Darvish S. Karimi A. Tehran Heart Center, homocysteine, vitamin B12 and folate levels in premature coronary artery disease.BMC Cardiovasc Disord. 2006; 6: 38

31. Wilcken D.E. Wilcken B. The pathogenesis of coronary artery disease. A possible role for methionine metabolism. J Clin Invest. 1976; 57: 1079-1082

32. Yajnik C.S. Deshpande S.S. Lubree H.G. Naik S.S. Bhat D.S. Uradey B.S. Deshpande J.A. Rege S.S. Refsum H. Yudkin J.S. Vitamin B12 deficiency and hyperhomocysteinemia in rural and urban Indians. J Assoc Physicians India. 2006; 54: 775-782

33. Whincup P.H. Refsum H. Perry I.J. Morris R. Walker M. Lennon L. Thomson A. Ueland P.M. Ebrahim S.B. Serum total homocysteine and coronary heart disease: 
prospective study in middle aged men. Heart. 1999; 82: 448-454

34. Boushey C.J. Beresford S.A.A. Omenn G.S. Motulsky A.G. A quantitative assessment of plasma homocysteine as a risk factor for vascular disease. JAMA. 1995; 274: 10491057

35. Stampfer M.J. Malinow M.R. Willett W.C. Newcomer L.M. Upson B. Ullmann D. Tishler P.V. Hennekens C.H. A prospective study of plasma homocyst(e)ine and risk of myocardial infarction in US physicians. JAMA. 1992; 268: 877-881

36. van Oijen M.G. Vlemmix F. Laheij R.J. Paloheimo L. Jansen J.B. Verheugt F.W. Hyperhomocysteinaemia and vitamin B12 deficiency: the long-term effects in cardiovascular disease. Cardiology. 2007; 107: 57-62

37. El-Gendi S.S. Bakeet M.Y. El-Hamed E.A. Ibrahim F.K. Ahmed R. The value of lipoprotein (a), homocysteine, and Doppler of carotid and femoral arteries in assessment of atherosclerosis in asymptomatic cardiovascular risk patients. J Cardiol. 2008; 52: 202-211

38. Kobori Y. Tanaka N. Matsuoka O. Aikawa M. Shindo N. Kobayashi H. Teramoto T. Takazawa K. Yamashina A. Tanaka N. Influence of serum homocysteine level on coronary atherosclerosis in Japanese. J Cardiol. 2004; 43: 223-229

39. Naono S. Tamura A. Kadota J. Plasma homocysteine level is unrelated to long-term cardiovascular events in patients with previous percutaneous coronary intervention. J Cardiol. 2009; 54: 21-28

40. Alfthan G. Pekkanen J. Jauhiainen M. Pitkäniemi J. Karvonen M. Tuomilehto J. Salonen J.T. Ehnholm C. Relation of serum homocysteine and lipoprotein(a) concentrations to atherosclerotic disease in a prospective Finnish population based study. Atherosclerosis. 1994; 106: 9-19

41. Sharma P. Kumar J. Garg G. Kumar A. Patowary A. Karthikeyan G. Ramakrishnan L. Brahmachari V. Sengupta S. Detection of altered global DNA methylation in coronary artery disease patients. DNA Cell Biol. 2008; 27: 357-365

42. Selhub J. Jacques P.F. Wilson P.W. Rush D. Rosenberg I.H. Vitamin status and intake as primary determinants of homocysteinemia in an elderly population. JAMA. 1993; 270: 2693-2698

43. Stabler SP. Clinical practice. Vitamin B12 deficiency. N Engl J Med 2013;368:149-60. 10.1056/NEJMcp1113996

[PubMed] [CrossRef] [Google Scholar]

44. Allen LH. How common is vitamin B-12 deficiency? Am J Clin Nutr 2009;89:693S6S. 10.3945/ajen.2008.26947A [PubMed] [CrossRef] [Google Scholar]

45. Keskin, E. Y., \& Keskin, M. (2015). Severe vitamin $\mathrm{B}_{12}$ deficiency in a 15-year-old boy: presentation with haemolysis and pancytopenia. BMJ case reports, 2015, bcr2015209718.

https://doi.org/10.1136/bcr-2015-209718

46. Heyssel R.M., Bozian R.C., Darby W.J., Bell M.C. Vitamin B12 turnover in man. The assimilation of vitamin B12 from natural foodstuff by man and estimates of minimal daily requirements. Am. J. Clin. Nutr. 1966;18:176-184

47. Stabler S.P., Allen R.H. Vitamin B12 deficiency as a worldwide problem. Annu. Rev. Nutr. 2004;24:299-326.

48. Watanabe F. Vitamin B12 sources and bioavailability. Exp. Biol. Med. 2007;232: 1266-1274

49. Casey P.J., Speckman K.R., Ebert F.J., Hobbs W.E. Radioisotope dilution technique for determination of vitamin B12 in foods. J. Assoc. Off. Anal. Chem. 1982;65:85-88.

50. Blake C.J. Analytical procedures for watersoluble vitamins in foods and dietary supplements: a review. Anal. Bioanal. Chem. 2007;389:63-76

51. Food and Nutrition Board, authors; National Research Council, editor. Dietary reference intakes for thiamin, riboflavin, niacin, vitamin B6, folate, vitamin B12, pantothenic acid, biotin and choline. National Academy Press; Washington, DC, USA: 1998. 
Institute of Medicine, Vitamin B12; pp. 306356

52. National Health and Medical Research Council, authors; Department of Health and Ageing, editor. Australian Government; Canberra, Australia: 2005. Nutrient Reference Values for Australia and New Zealand; pp. 91-96

53. Valuck R.J., Ruscin J.M. A case-control study on adverse effects: H2 blocker or proton pump inhibitor use and risk of vitamin B12 deficiency in older adults. J. Clin. Epidemiol. 2004;57:422-428.

54. Dharmarajan T.S., Kanagala M.R., Murakonda P., Lebelt A.S., Norkus E.P. Do acid-lowering agents affect vitamin B12 status in older adults? J. Am. Med. Dir. Assoc. 2008;9:162-167. doi:10.1016/ j.jamda. 2007.10.004.
55. Filioussi K., Bonovas S., Katsaros T. Should we screen diabetic patients using biguanides for megaloblastic anaemia? Aust. Fam. Physician. 2003;32:383-384.

56. Bauman W.A., Shaw S., Jayatilleke E., Spungen A.M., Herbert V. Increased intake of calcium reverses vitamin B12 malabsorption induced by metformin. Diabetes Care. 2000;23:1227-1231

57. Schilling R.F. Is nitrous oxide a dangerous anesthetic for vitamin B12- deficient subjects? JAMA. 1986;255:1605-1606.

58. Siniscalchi A., Mancuso F., Gallelli L., Ferreri I., Biagio M., Sarro G.D. Increase in plasma homocysteine levels induced by drug treatments in neurologic patients. Pharmacol. Res. 2005;52:367-375 